\title{
Estimating the Electrochemically Active Area: Revisiting a Basic Concept in Electrochemistry
}

\author{
Dyovani Coelho, ${ }^{a}$ Giuliana M. Luiz ${ }^{a}$ and Sergio A. S. Machado ${ }^{\circledR *, a}$ \\ ${ }^{a}$ Grupo de Materiais Eletroquímicos e Métodos Eletroanalíticos, Instituto de Química de São Carlos, \\ Universidade de São Paulo, 13566-590 São Carlos-SP, Brazil
}

\begin{abstract}
The well-known electrochemical probe $\mathrm{Fe}(\mathrm{CN})_{6}{ }^{3-} / \mathrm{Fe}(\mathrm{CN})_{6}{ }^{4-}$ is widely used for estimating the electrochemically active area of electrodes modified with carbon nanotubes, conductive polymers, enzymes, etc. In this study, we used the platinum electrode, smooth or platinized with different roughness factors, to demonstrate that such a redox couple fails to respond to a surface roughness variation. We determined the roughness factors of the Pt surfaces by atomic force microscopy (AFM) images, which yielded values between 2.72 and 25.91. Almost the same values were found by using the charge of the hydrogen monolayer desorption obtained from steady-state cyclic voltammetry experiments performed in an acid medium. They were then compared with those provided by peak current in voltammetry or chronoamperometry with $\mathrm{Fe}(\mathrm{CN}){ }_{6}{ }^{3-} / \mathrm{Fe}(\mathrm{CN}){ }_{6}{ }^{4-}$ which all yielded values nearly to one. Such comparison demonstrates that the electrochemical behavior of the redox probe is an outer sphere reaction with a quite small interaction with the electrode surface, thus not being suitable to be related with active areas.
\end{abstract}

Keywords: electrochemical area, potassium ferrocyanide, electrode area, cyclic voltammetry, chronoamperometry

\section{Introduction}

Electrochemistry started being developed by, mainly, employing the mercury drop electrode. Such an electrode presents a unique characteristic that simplified the initial task: it has a completely homogeneous surface with a roughness factor equal to one. Consequently, the electrochemical area is the same as the geometric area of the drop. In this way, parameters that depend on active areas such as current densities or kinetic constants, are promptly associated with the easily measurable geometric (equals to electrochemical) area. This comfortable situation changed dramatically when electrochemistry marched towards the solid electrodes' quagmire. Electrodes surfaces such as glassy carbon, platinum, gold, nickel, or oxides even when mirror-like polished, present a surface roughness factor considerably higher than one. Therefore, their real area is always larger than the geometric one. This becomes even worse when we consider heterogeneous surfaces like oxides. What part of them is active for a given electrochemical reaction? Of course, some solid electrodes have an electrochemical

*e-mail: sasmach@iqsc.usp.br area that is simple to be determined. This is the case for platinum, which area can be calculated through the charge required to desorb a hydrogen monolayer ${ }^{1}$ or by others methods ${ }^{2}$ and gold, with the charge required for oxide reduction. ${ }^{3}$ The utmost importance of understanding concepts such as geometric and active areas, roughness and heterogeneity, and others that are associated with the local surface properties had been stressed by Trasatti and Petrii ${ }^{3}$ who, inclusive commented that the use of cyclic voltammetry with a redox couple may lead to a flattened area, similar to the geometric one. The challenge of the electrochemical area evaluation acquired an extraordinary dimension since the work of electrochemistry researchers moved to chemically modified electrodes. These electrodes present their surfaces covered with, e.g., conducting polymer, ${ }^{4}$ carbon nanotubes, ${ }^{5}$ self-assembled monolayers, ${ }^{6}$ or graphene. ${ }^{7}$

On such complicated mixed surfaces, with quite high roughness factors, where are the catalytic centers on which the electrochemical reaction proceeds? What portion of the surface is, then, active for the electrochemical process? To find some answers to such questions, several researchers around the world opted to use the voltammetric peak currents obtained from the ferrocyanide/ferricyanide redox 
couple and compared to those obtained on smooth platinum or gold surface. Then, they calculate the area factor between both surfaces or apply theoretical equations (RandlesSevcik, Cottrell) to access the electrochemical area of such electrodes. ${ }^{8-14}$ From such publications, among many others in the literature, it can be found roughness factors ranging from 1.2 to 2.5 , which seems unlikely since the coverages with, for example, carbon nanotubes or graphene layers, are rather porous. Glassy carbon electrodes present a quite smooth surface. In this sense, roughness factors as those reported, all calculated using voltammetric data from the $\mathrm{Fe}(\mathrm{CN})_{6}{ }^{4-} / \mathrm{Fe}(\mathrm{CN})_{6}{ }^{3-}$ probes, are meaningless. Even the high-resolution microscopy data included in most of such work clearly show that the surface roughness is much larger than the calculated. Why this happens so often?

Both Randles-Sevcik and Cottrell equations are derived from Fick's laws of diffusion that consider the flux of electroactive species through a plane parallel to the electrode surface. The distance of such a plane depends on the time scale of the experiment. For voltammograms or chronoamperograms, in the time scale of a few seconds (most common in electrochemical experiments), such plane is located at hundreds of micrometers from the electrode surface. ${ }^{15}$ Considering the dimension of the surface roughness in the order of nanometers, such distance is high enough for the diffusion plane to not detect any surface irregularity. Therefore, the area (A) in such equations are the geometric one. To detect the surface roughness, the time scale should be in the order of nanoseconds, a scan rate of thousands of volts per second in voltammetric experiments, which is far beyond the experimental conditions of most papers in the literature. Such theoretical explanations are explored by Paixão ${ }^{16}$ in a very recent paper.

In this work the redox pair $\mathrm{Fe}(\mathrm{CN})_{6}{ }^{4-} / \mathrm{Fe}(\mathrm{CN})_{6}{ }^{3-}$ was used to experimentally evaluate the electrochemical area of several platinum surfaces with different roughness factors and to compare with those determined by the charge of the hydrogen monolayer desorption and atomic microscopy images.

\section{Experimental}

All solutions were prepared with purified water from a Barnstead Nanopure System (Thermo Scientific, USA), with resistivity $\geq 18 \mathrm{M} \Omega \mathrm{cm}$. All reagents used in this study were of analytical grade and were used without further purification.

Cyclic voltammetry and chronoamperometry experiments were performed using a model PGSTAT30 Autolab electrochemical system (Eco Chemie, Utrecht, Netherlands) equipped with GPES software (Eco Chemie,
Utrecht, Netherlands). The electrochemical cell was assembled with a conventional three-electrode set-up including a smooth or platinized $\mathrm{Pt}$ as working electrodes (Pt disc with a measured geometric area of $0.0314 \mathrm{~cm}^{2}$, embedded in poly(tetrafluoroethene) (PTFE)); $\mathrm{Ag} / \mathrm{AgCl} /$ $\mathrm{KCl}\left(3.0 \mathrm{~mol} \mathrm{~L}^{-1}\right)$ as the reference system; and a Pt plate as the auxiliary electrode. All experiments were carried out at $25^{\circ} \mathrm{C}$.

The surface morphology of each material was characterized using a Nanosurf EasyScan 2 atomic force microscope from Nanosurf Inc. (Lausanne, Swiss).

The following reactants were used to prepare the solutions for the electrochemical experiments: potassium ferrocyanide (J. T. Baker, Aparecida de Goiania, Brazil), potassium ferricyanide (Mallinckrodt, Dublin, Ireland), sulfuric acid (98.0\%) Labsynth (São Paulo, Brazil), $\mathrm{HCl}$ (36.0\%), $\mathrm{AgNO}_{3}, \mathrm{KCl}$, and $\mathrm{Na}_{2} \mathrm{SO}_{4}$ (J. T. Baker, Aparecida de Goiania, Brazil) and $\mathrm{H}_{2} \mathrm{PtCl}_{6}$ (Sigma-Aldrich, Saint Louis, USA). All others reagents were purchased from Sigma-Aldrich (Saint Louis, USA).

The pre-treatment for the smooth platinum surface involved the following steps: $(i)$ mechanical polishing, (ii) chemical oxidation, and (iii) electrochemical annealing. The mechanical polishing was performed with emery paper (grids 1200, 2000, and 4000) and alumina suspensions (1.0, $0.3 \mu \mathrm{m}$ suspended in water). The polishing yielded a mirror-like surface. After this procedure, the electrode was sonicated in purified water for residual particle elimination. The chemical oxidation of possible contaminants in the electrode surface was carried out by the immersion in a piranha solution $\left(1: 3 \mathrm{H}_{2} \mathrm{O}_{2}: \mathrm{H}_{2} \mathrm{SO}_{4}\right.$, respectively) for $5 \mathrm{~min}$ following by extensive water washing. The electrochemical annealing was performed using cyclic voltammetry in the potential window of -0.22 and $1.1 \mathrm{~V}$ (vs. $\mathrm{Ag} / \mathrm{AgCl})$ using $0.1 \mathrm{~mol} \mathrm{~L}^{-1} \mathrm{H}_{2} \mathrm{SO}_{4}$ as support electrolyte. The conditioning step consisted in applying, on the electrode surface, 100 cycles at $1 \mathrm{~V} \mathrm{~s}^{-1}, 50$ cycles at $0.5 \mathrm{~V} \mathrm{~s}^{-1}, 25$ cycles at $0.25 \mathrm{~V} \mathrm{~s}^{-1}$ and 10 cycles at $0.1 \mathrm{~V} \mathrm{~s}^{-1}$. This extensive clean-up procedure succeeded to yield a clean Pt surface with a voltammetric profile that was quite like those previously reported $^{1,2}$ as can be seen in Figure 1.

The integration of $\mathrm{H}$ desorption peaks was performed with the Origin v.8 software. ${ }^{17}$

\section{Results and Discussion}

To obtain a platinum surface with different roughness factors, the potentiostatic method used by Feltham and Spiro, ${ }^{18}$ for platinum electrodeposition was carried out in $10 \mathrm{~mL}$ of a $0.1 \mathrm{~mol} \mathrm{~L}^{-1} \mathrm{H}_{2} \mathrm{SO}_{4}+1.0 \mathrm{mmol} \mathrm{L}^{-1}$ $\mathrm{H}_{2} \mathrm{PtCl}_{6}$ solution with the electrode polarized at $-0.2 \mathrm{~V}$ for 


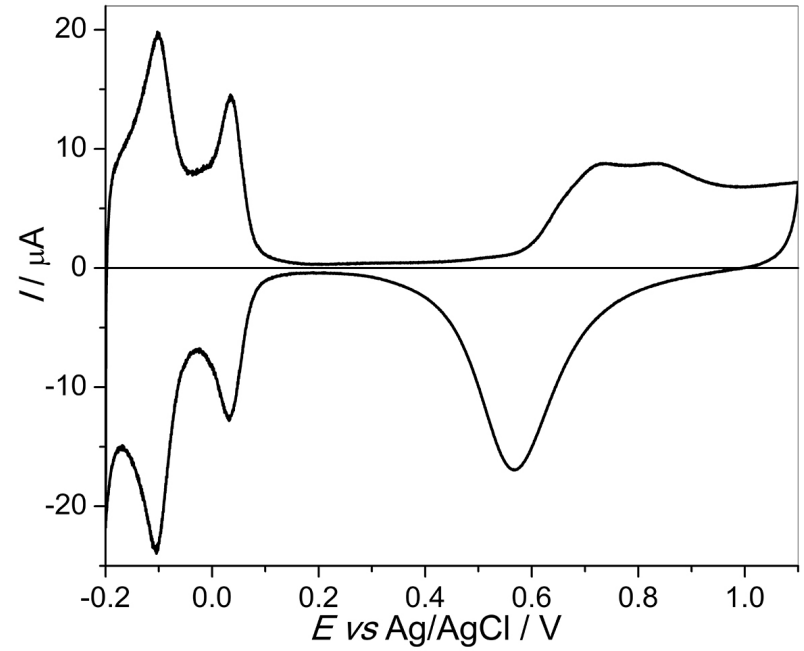

Figure 1. Steady-state cyclic voltammogram for smooth $\mathrm{Pt}$ in $0.5 \mathrm{~mol} \mathrm{~L}^{-1} \mathrm{H}_{2} \mathrm{SO}_{4}$ at $0.1 \mathrm{~V} \mathrm{~s}^{-1}$.

$0,5,40,320,1280$ and $2560 \mathrm{~s}$ and a constant stirring value. The results of such a procedure are presented in Figure 2, where atomic force microscopy (AFM) images show the increase in surface roughness with the electrodeposition time, quantified by the mean square roughness $(\mathrm{Sq})$ parameter, as calculated from the AFM software. This parameter represents the mean value of all the differences between valley depth and peak height in the $\mathrm{N}$ lines swept in interest, by the atomic force cantilever. ${ }^{19}$ The roughness factor of the surface increases with the deposition time.
The steady-state cyclic voltammograms for the six different Pt surfaces (Figure 2) in $0.5 \mathrm{~mol} \mathrm{~L}^{-1} \mathrm{H}_{2} \mathrm{SO}_{4}$, at $100 \mathrm{mV} \mathrm{s}^{-1}$ are all presented in Figure 3. The voltammetric profile is associated with electroreactions of adsorbed reagents (oxygen for $\mathrm{PtO}$ formation and reduction at potentials more positive than $0.5 \mathrm{~V}$ and hydrogen for $\mathrm{PtH}_{\text {ads }}$ deposition and dissolution at potentials more negative than $0.1 \mathrm{~V}) .{ }^{20}$ Such electrochemical reactions are dependent on the real surface areas and the voltammetric currents increase with the roughness factors. Indeed, the anodic charges in a potential region more negative than $0.5 \mathrm{~V}$ are usually the parameter employed to evaluate the electrochemical area of Pt surfaces. In this potential window, the voltammetric profile is associated with the electrochemical reaction:

$\mathrm{Pt}-\mathrm{H}_{\mathrm{ads}} \rightarrow \mathrm{Pt}+\mathrm{H}^{+}+\mathrm{e}^{-}$

Considering that, on a typical polycrystalline $\mathrm{Pt}$ surface an atomic density of $1.30 \times 10^{15}$ atoms $\mathrm{cm}^{-2}$ is generally accepted by electrochemical researchers ${ }^{21,22}$ and that each surface Pt atom is associated with one adsorbed hydrogen atom, the reaction 1 assures that $210 \mu \mathrm{C} \mathrm{cm}^{-2}$ is transferred for the desorption of a full $\mathrm{H}$ monolayer. ${ }^{1,21,22}$ Thus, the $\mathrm{H}$ anodic desorption charges obtained from the voltammograms in Figure 3 give the electrochemical (or real) electrode area.
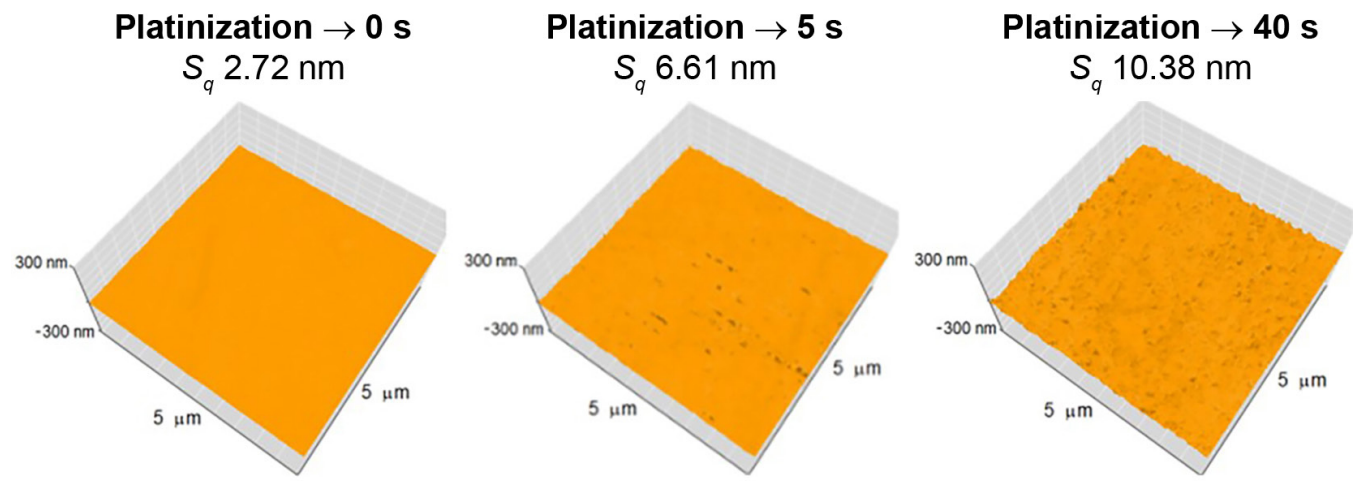

Platinization $\rightarrow 320 \mathrm{~s}$ $S_{q} 13.89 \mathrm{~nm}$

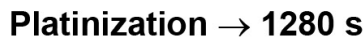
$S_{q} 18.82 \mathrm{~nm}$

Platinization $\rightarrow 2560 \mathrm{~s}$ $S_{q} 25.91 \mathrm{~nm}$
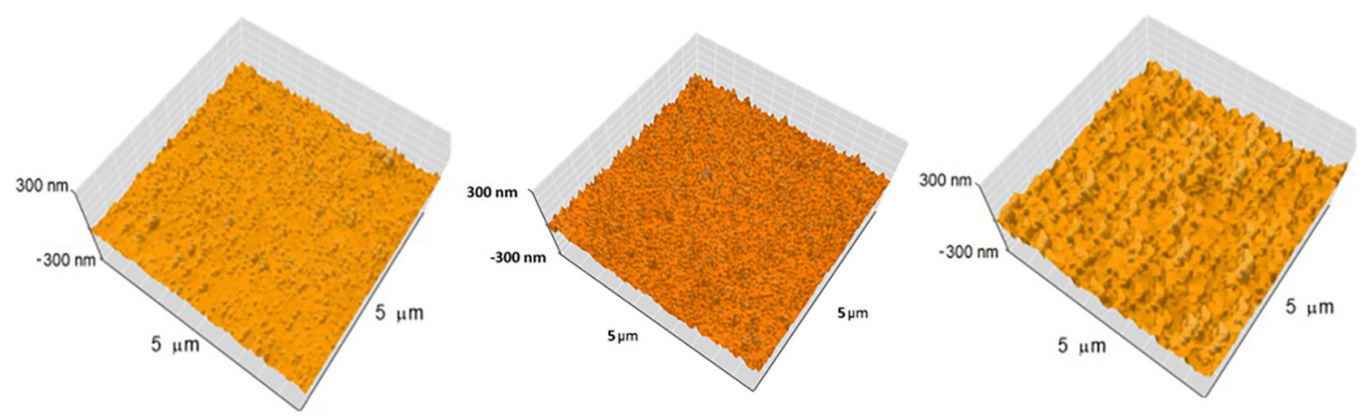

Figure 2. AFM images for platinized Pt electrode with different electrodeposition times at $-0.2 \mathrm{~V} v s$. Ag/AgCl: $0,5,40,320,1280$ and $2560 \mathrm{~s}$. 


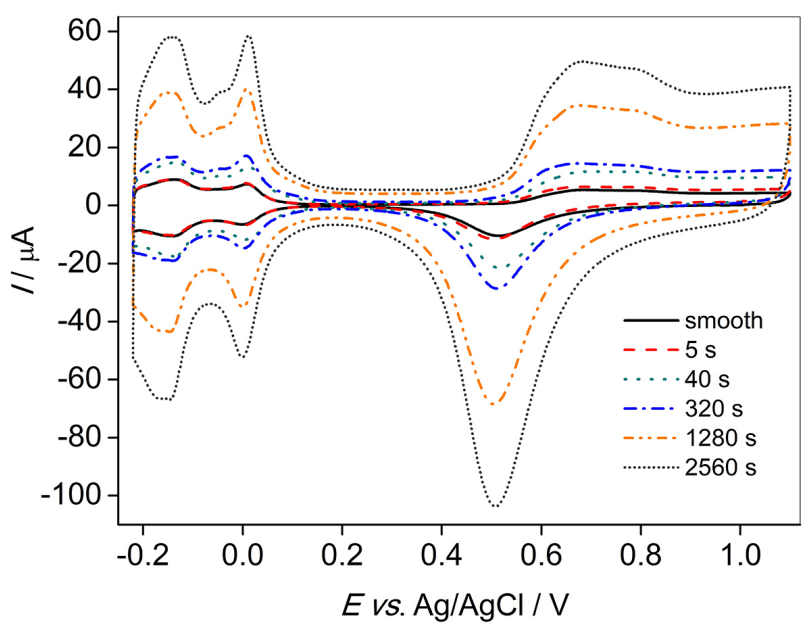

Figure 3. Cyclic voltammetry for different roughness factors Pt electrodes (as in Figure 1) in $0.5 \mathrm{~mol} \mathrm{~L}^{-1} \mathrm{H}_{2} \mathrm{SO}_{4}$, at a scan rate of $0.1 \mathrm{~V} \mathrm{~s}^{-1}$.

The values of the electrochemical areas, obtained either by cyclic voltammetry or atomic force microscopy, are collected in Table 1. The roughness factors from AFM images multiplied by the geometric area of the electrode, i.e., $0.031 \mathrm{~cm}^{2}$, yielded (in an extremely rough manner) the electrochemical area.

Table 1. Comparison between the electrochemical areas obtained by cyclic voltammetry (EA CV) and atomic force microscopy (EA AFM)

\begin{tabular}{lcccc}
\hline $\begin{array}{l}\text { Platinization } \\
\text { time / s }\end{array}$ & $\begin{array}{c}\mathrm{CV} \\
\text { roughness } \\
\text { factor }\end{array}$ & $\begin{array}{c}\mathrm{EA} \mathrm{CV} / \\
\mathrm{cm}^{2}\end{array}$ & $\begin{array}{c}\text { AFM } \\
\text { roughness } \\
\text { factor }\end{array}$ & $\begin{array}{c}\text { EA AFM / } \\
\mathrm{cm}^{2}\end{array}$ \\
\hline 0 & 2.45 & 0.077 & 2.72 & 0.085 \\
5 & 1.87 & 0.059 & 6.61 & 0.208 \\
40 & 2.58 & 0.081 & 10.38 & 0.326 \\
320 & 4.61 & 0.145 & 13.89 & 0.436 \\
1280 & 9.75 & 0.306 & 18.82 & 0.591 \\
2560 & 19.29 & 0.606 & 25.91 & 0.813 \\
\hline
\end{tabular}

Despite the evident differences in some individual values, mainly caused by the distinct significances in the methodologies of the calculations, it is evident that the increase in the electrochemical area follows the same trend in both evaluations. The roughness factor values obtained for a smooth, mirror-like polished Pt surface are both above two, as expected for solid surfaces. ${ }^{15}$

The electrochemical behavior of $\mathrm{Fe}(\mathrm{CN})_{6}{ }^{4-} / \mathrm{Fe}(\mathrm{CN})_{6}{ }^{3-}$ probe was investigated on Pt electrodes of different roughness factors, as presented in Figure 2. The steady-state cyclic voltammetry was performed in $0.5 \mathrm{~mol} \mathrm{~L}^{-1} \mathrm{H}_{2} \mathrm{SO}_{4}$ at $0.1 \mathrm{~V} \mathrm{~s}^{-1}$ containing $5.0 \times 10^{-4} \mathrm{~mol} \mathrm{~L}^{-1}$ of both, $\mathrm{K}_{4} \mathrm{Fe}(\mathrm{CN})_{6}$ and $\mathrm{K}_{3} \mathrm{Fe}(\mathrm{CN})_{6}$, and the results are presented in Figure 4. From that figure, it can be calculated the peaks potentials separation, $\Delta \mathrm{E}_{\mathrm{p}}$, for each platinization time. The values ranged from 66 to $75 \mathrm{mV}$, independent of the roughness of the surface. Also, the peaks currents relationship, $\mathrm{I}_{\mathrm{pa}} / \mathrm{I}_{\mathrm{pc}}$, were always near to one.

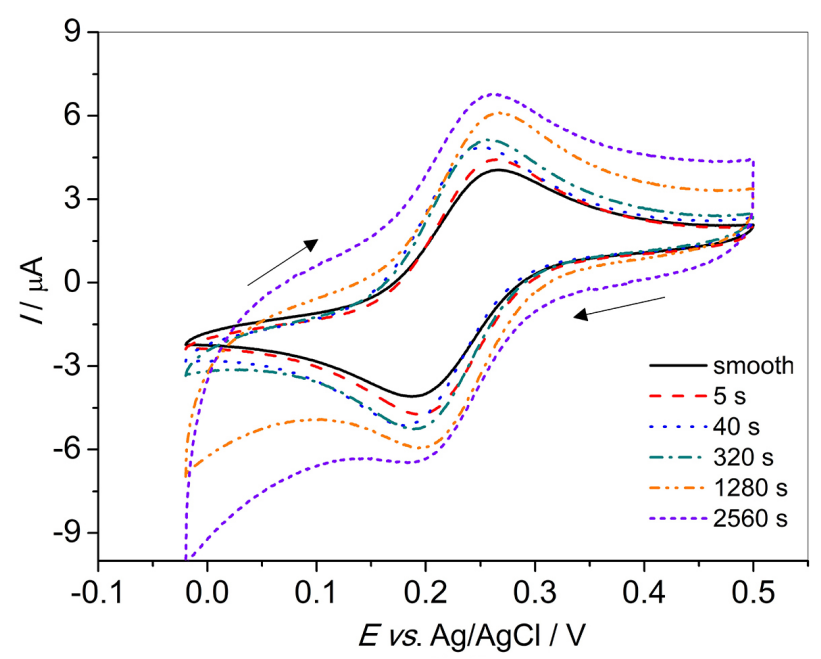

Figure 4. Steady-state cyclic voltammograms of Pt electrodes with different platinization times in $0.5 \mathrm{~mol} \mathrm{~L}^{-1} \mathrm{H}_{2} \mathrm{SO}_{4}+5.0 \times 10^{-4} \mathrm{~mol} \mathrm{~L}^{-1}\left[\mathrm{Fe}(\mathrm{CN})_{6}\right]^{4-13-}$ at $0.1 \mathrm{~V} \mathrm{~s}^{-1}$.

Although the visual increase in the peak current of the redox couple with platinization time could be evident if one considers the proper baseline for the voltammograms the effect itself is not enough to justify the increase in the roughness factor, as seen, for example, in Table 1. If one uses the Randles-Sevcik equation: ${ }^{15}$

$\mathrm{I}_{\mathrm{p}}=\left(2.69 \times 10^{5}\right) \mathrm{n}^{3 / 2} \mathrm{AC} \mathrm{D}_{0}^{1 / 2} v^{1 / 2}$

where $I_{p}$ is the peak current, $n$ is the number of electrons transferred, $\mathrm{A}$ is the electrochemical area, $\mathrm{C}$ is the analyte concentration, $\mathrm{D}_{\mathrm{o}}$ is the diffusion coefficient for the oxidized species, and $v$ is the scan rate. With Do equals to $7.17 \times 10^{-6} \mathrm{~cm}^{2} \mathrm{~s}^{-1},{ }^{23}$ it is possible to obtain the area values, collected in Table 2. Further insight into the electrochemical behavior of $\mathrm{Fe}(\mathrm{CN})_{6}{ }^{4-}$ is possible with chronoamperometric experiments, which results are depicted in Figure 5 as the chronoamperograms of different roughness factors $\mathrm{Pt}$ surfaces in $\mathrm{H}_{2} \mathrm{SO}_{4} 0.5 \mathrm{~mol} \mathrm{~L}^{-1}+\mathrm{K}_{4}\left[\mathrm{Fe}(\mathrm{CN})_{6}\right] 5.0 \times 10^{-4} \mathrm{~mol} \mathrm{~L}^{-1}$. Using the Cottrell equation: ${ }^{15}$

$I_{d}=\operatorname{nFACDo}^{1 / 2} \pi^{-1 / 2} \mathrm{t}^{-1 / 2}$

where $I_{d}$ is the diffusion current, $F$ is the Faraday constant, $\mathrm{C}$ is the analyte concentration and $\mathrm{t}$ is the transient time.

The surface area can also be calculated by measuring the diffusional current values, which were performed in the time region showed in the insert of Figure 5. The results obtained from Figure 5 are also included in Table 2. 


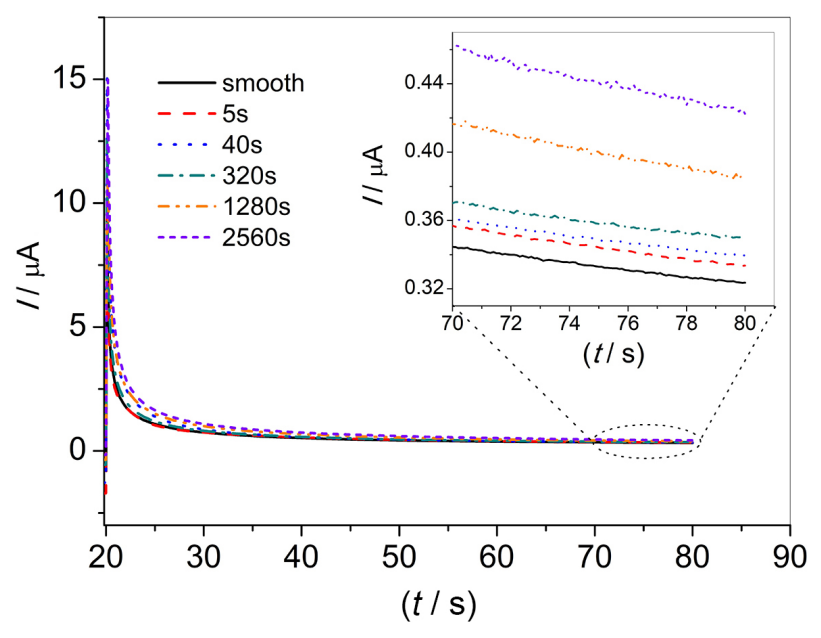

Figure 5. Chronoamperograms for Pt electrodes in $0.5 \mathrm{~mol} \mathrm{~L}^{-1} \mathrm{H}_{2} \mathrm{SO}_{4}+$ $5.0 \times 10^{-4} \mathrm{~mol} \mathrm{~L}^{-1} \mathrm{~K}_{4}\left[\mathrm{Fe}(\mathrm{CN})_{6}\right]$. Initial potential, $\mathrm{E}_{\mathrm{i}}=0.0 \mathrm{~V}$, final potential, $\mathrm{E}_{\mathrm{f}}=0.45 \mathrm{~V}$.

Here, the variation of the electrochemical area values with roughness factor is still smaller than those observed in Figure 3 for the voltammetric peak current values. The diffusion-limited current seems to barely depend on the surface roughness.

Table 2. Comparison between the electrochemical areas obtained by cyclic voltammetry (EA CV) and chronoamperometry (EA CA) with $5.0 \times 10^{-4} \mathrm{~mol} \mathrm{~L}^{-1} \mathrm{~K}_{4}\left[\mathrm{Fe}(\mathrm{CN})_{6}\right]$

\begin{tabular}{lccc}
\hline $\begin{array}{l}\text { Platinization } \\
\text { time / s }\end{array}$ & $\begin{array}{c}\text { EA CV / } \\
\mathrm{cm}^{2}\end{array}$ & $\begin{array}{c}\text { CA diffusion } \\
\text { limit currents / } \\
\left(\times 10^{-6} \mathrm{~A}\right)\end{array}$ & $\begin{array}{c}\text { EA CA / } \\
\mathrm{cm}^{2}\end{array}$ \\
\hline 0 & 0.036 & 0.32 & 0.037 \\
5 & 0.039 & 0.33 & 0.038 \\
40 & 0.043 & 0.34 & 0.039 \\
320 & 0.045 & 0.35 & 0.040 \\
1280 & 0.054 & 0.38 & 0.044 \\
2560 & 0.059 & 0.42 & 0.048 \\
\hline
\end{tabular}

The similarity between the data presented in columns 2 and 4 in Table 2 is evident. A more detailed analysis reveals that for a smooth Pt surface (platinization time equaling zero) the "electrochemical area" obtained for both methods above with $\mathrm{Fe}(\mathrm{CN})_{6}{ }^{4-}$ and $\mathrm{Fe}(\mathrm{CN})_{6}{ }^{3-}$ are almost identical to the geometric one, as shown above $\left(0.031 \mathrm{~cm}^{2}\right)$.

Considering the set of experimental data in Table 2, it is possible to obtain roughness factor values varying from 1.2 (smooth surface) to 1.5, chronoamperometric data obtained for the Pt surface modified with $2560 \mathrm{~s}$ of platinization. This is in clear disagreement with the data provided in Table 1, where the voltammetric experiments for $\mathrm{H}_{\text {ads }}$ desorption provided the highest roughness factor value in the same experimental condition: ca. 20 . The values for roughness factors showed in Table 2, although wrong, are in perfect agreement with several values found in the literature for different modified electrode surfaces (graphenes, carbon nanotubes, metal oxides, conducting polymers) obtained with the ferrocyanide/ferricyanide redox couple..$^{24-27}$

To finalize the comparison between distinct methodologies used to estimate the electrochemical area, which is directly associated with the obtained roughness factors, of electrodes, Figure 6 collects the results discussed above, in the form of a relationship between roughness factors and platinization times.

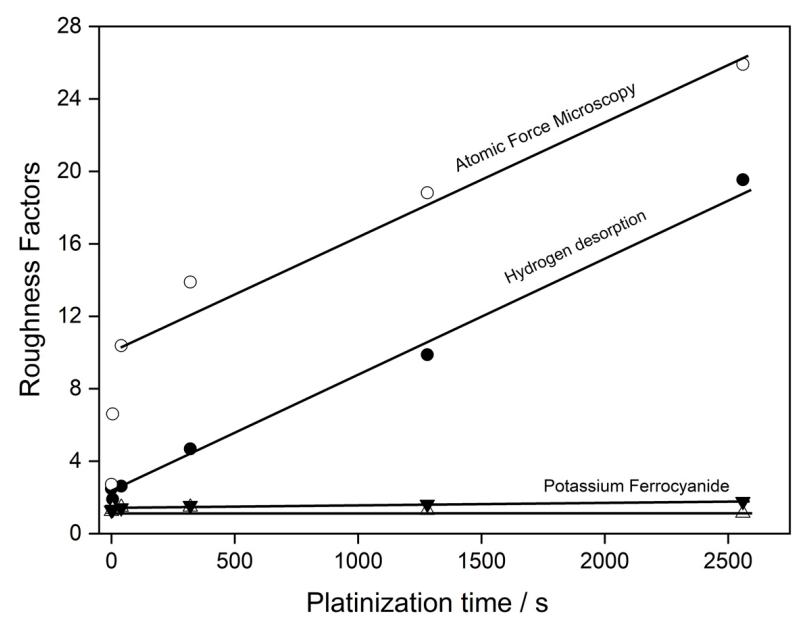

Figure 6. Roughness factors as a function of the platinization time for the different methods used to estimate the working electrode real area.

Although the differences observed between hydrogen desorption and atomic force microscopy can be associated with a bias related to different definitions of surface roughness in both methodologies (same slope of the straight line but different linear coefficients), it is possible to argue that both respond equally to the variation of the platinization time and, consequently, to the surface roughness.

The voltammetric and chronoamperometric responses obtained for the redox couple, potassium ferrocyanide/ ferricyanide, were quite different. The comparison in Figure 6 is illustrative. The voltammetric peak currents and the diffusion currents do not vary significantly with an increase in the surface roughness. The straight lines are almost parallel to the $x$-axis.

This independent behavior is a shred of experimental evidence that voltammograms or chronoamperograms with this redox couple, although quite common in literature, cannot be used to evaluate electrochemical areas or surface roughness of the electrode.

\section{Conclusions}

The experimental results discussed here strongly suggested that the use of ferrocyanide/ferricyanide redox 
couple in the determination of the electrochemical (active) electrode area fails to provide trustful values for a platinum surface and, by extrapolation, for any electrode surface, such as carbon nanotubes, conductive polymers, and modified surfaces.

This is related to the fact that the redox reaction $\mathrm{Fe}(\mathrm{CN})_{6}{ }^{4-} / \mathrm{Fe}(\mathrm{CN})_{6}{ }^{3-}$ is an outer sphere process, with minimal interaction with the electrode surface. The peak currents, as well as the chronoamperometric limit diffusion currents, are only functions of the geometric area, defined simply by the diffusion plane parallel to the electrode surface, which presents no "surface roughness" in the period of such experiments. This is quite evident when one considers the data included in Table 2, where the calculated roughness factors are all very close to one. To consider that the diffusion plane follows the surface topology, one must conduct voltammetric experiments with scan rates as high as $10,000 \mathrm{~V} \mathrm{~s}^{-1}$ to minimize the growth of the diffusion layer away from the electrode surface.

In conclusion, it should be imperative to researchers to stop using the voltammetric currents or chronoamperometric diffusion currents of ferrocyanide/ferricyanide redox couple to evaluate the electrochemical area for different electrodes.

\section{Acknowledgments}

We are grateful for the financial support from CAPES, FAPESP (2011/07022-4, 2013/17053-0), and CNPq (Proc. 471389/2013-7).

\section{References}

1. Gilman, S.; J. Phys. Chem. 1963, 67, 78.

2. Chen, D.; Tao, Q.; Liao, L. W.; Liu, S. X.; Chen, Y. X.; Ye, X. S.; Electrocatalysis 2011, 2, 207.

3. Trasatti, S.; Petrii, O.; J. Electroanal. Chem. 1992, 327, 353.

4. Lou, B.; Chen, C.; Zhou, Z.; Zhang, L.; Wang, E.; Dong, S.; Talanta 2013, 105, 40.

5. Fagan-Murphy, A.; Patel, B. A.; Electrochim. Acta 2014, 138, 392.
6. Arduini, F.; Guidone, S.; Amine, A.; Palleschi, G.; Moscone, D.; Sens. Actuators, B 2013, 179, 201.

7. Zhang, Z.; Yan, J.; Jin, H.; Yin, J.; Electrochim. Acta 2014, 139 , 232.

8. Liu, L.; Gou, Y.; Gao, X.; Zhang, P.; Chen, W.; Feng, S.; Hu, F.; Li, Y.; Mater. Sci. Eng., C 2014, 42, 227.

9. Chen, X.; Zhu, J.; Xi, Q.; Yang, W.; Sens. Actuators, B 2012 , 161,648 .

10. Jain, R.; Tiwari, D. C.; Shrivastava, S.; Mater. Sci. Eng., B 2014, 185, 53.

11. Dorraji, P. S.; Jalali, F.; Sens. Actuators, B 2014, 200, 251.

12. Wang, F.; Yang, J.; Wu, K.; Anal. Chim. Acta 2009, 638, 23.

13. Naik, K. M.; Nandibewoor, S. T.; Anal. Methods 2013, 5, 6947.

14. Naik, K. M.; Nandibewoor, S. T.; Sens. Actuators, A 2014, 212 , 127.

15. Bard, A. J.; Faulkner, L. R.; Electrochemical Methods, Fundamentals and Applications, $2^{\text {nd }}$ ed.; John Wiley and Sons: New York, USA, 2001.

16. Paixão, T. R. L. C.; ChemElectroChem 2020, 7, 3414.

17. Origin v.8; OriginLab Corporation, MA, USA, 2020.

18. Feltham, A. M.; Spiro, M.; Chem. Rev. 1971, 71, 177.

19. Nanosurf EasyScan 2, Operation Instructions version 2.2; Nanosurf AG 2006: Liestal, Switzerland, p. 215.

20. Angerstein-Kozlowska, H.; Conway, B. E.; Sharp, W. B. A.; J. Electroanal. Chem. Interfacial Electrochem. 1973, 43, 9.

21. Biegler, T.; Rand, D. A. J.; Woods, R.; J. Electroanal. Chem. Interfacial Electrochem. 1971, 29, 269.

22. Cesarino, I.; Cesarino, V.; Lanza, M. R. V.; Sens. Actuators, B 2013, 188, 1293.

23. Baur, J. E.; Wightman, R. M.; J. Electroanal. Chem. 1991, 305, 73.

24. Schröper, F.; Brüggemann, D.; Mourzina, Y.; Wolfrum, B.; Offenhäusser, A.; Mayer, D.; Electrochim. Acta 2008, 53, 6265.

25. Navarro-Laboulais, J.; Trijueque, J.; García-Jareño, J. J.; Benito, D.; Vicente, F.; J. Electroanal. Chem. 1998, 443, 41.

26. García-González, R.; Costa-García, A.; Fernández-Abedul, M. T.; Sens. Actuators, B 2014, 202, 129.

27. Reddaiah, K.; Reddy, T. M.; J. Mol. Liq. 2014, 196, 77.

Submitted: March 25, 2021

Published online: May 27, 2021 